Journal of Engineering and Science Research 4 (1): 28-34, 2020

e-ISSN: 2289-7127

(C) RMP Publications, 2020

DOI: $10.26666 / \mathrm{rmp}$.jesr.2020.1.5

\title{
Transition towards a sustainable heating sector in municipality of Visoko with analysis of loading and optimization of solar collector carriers
}

\author{
${ }^{1}$ M. Petrovic, ${ }^{2}$ A. Babic and ${ }^{2}$ E. Fejzovic \\ ${ }^{1}$ Mechanical Engineering Faculty, University of Sarajevo, 71000 Sarajevo, Bosnia and Herzegovina \\ ${ }^{2}$ Municipality of Visoko, 71300 Visoko, Bosnia and Herzegovina
}

\begin{abstract}
Many traditional heating systems based on fossils face challenges such as lack of investment or unfavorable price regulation, low technical performance, impact on the environment and negative consumer perceptions. The CoolHeating project funded by the EU's Horizon 2020 program, whose basic features and outcomes are presented in this work, promotes the implementation of small modular renewable heating and cooling grids for communities in South-Eastern Europe, including the town of Visoko as one of five target regions. Core activities, besides techno-economical assessments and social-environmental benefits, include measures to stimulate the interest of communities and citizens to set-up renewable district heating systems.

In this work, an analysis was performed for implementation of small modular district heating system in Visoko, covering several public buildings and few neighborhoods in north-western part of town. Combination of different renewable energy sources were analyzed leading to an optimal and a very promising energy supply strategy due to its contribution to security of supply, financial stability, local economic development, local employment, etc. Possible financial savings for heating of $38 \%$ compared to current financial needs are determined. Structure optimization of solar collector holders was also performed, taking into account external influence, enabling savings in the structure material.

This approach confirms feasibility of transition from traditional to renewable energy based heating system. Having in mind the modularity of such systems, similar solutions can be replicated in other South-Eastern European cities and other countries.
\end{abstract}

Key words: Modular district heating grids, Renewable energy sources, Heat storage, Heat pumps, Solar collectors, Structural optimization, Cost-effectiveness

\section{INTRODUCTION}

Although the heating and cooling sector is moving to clean low carbon energy, the proportion of heat supply from fossil fuels is still very high, both in the world (90\%) and in the European Union (70\%), since fossil fuels are still the main energy supply group for both CHP and boiler plants [1]. In Europe, the heating and cooling demand accounts for around $50 \%$ of the EU's final energy consumption. In order to reduce carbon dioxide emissions in heating/cooling sector, new non-fossil heat sources must replace the current fossil-based plants. District heating (DH) as an efficient solution for heat supply and distribution can play a major part in meeting decarbonisation targets. According to the EU Strategy on Heating and Cooling (2016), the contribution of DH in the EU accounts for $9 \%$ and is mainly driven by fossil fuels such as gas and coal [2]. District and cooling heating networks present a high potential for the transition of the heat/cooling sector, both technically and organizationally [3]. They allow integration of renewable energies, improve the overall energy efficiency, as well as facilitate sector coupling (coupling between heating, electricity and mobility) [4,5]. In order to use this potential, many district heating networks must first upgrade the existing distribution system, including the substations and consumer connections: reaching lower leakage rates and heat losses, reducing operation temperatures, adapting piping dimensions and hydraulic, introducing modern IT-based management systems and options for user control. This makes the heat distribution more efficient, but also improves the efficiency of the

Corresponding Author: M. Petrovic, University of Sarajevo, Vilsonovo setaliste 9, 71000 Sarajevo, Bosnia and Herzegovina 
heat generation, saving the primary energy. Moreover, it allows the integration of renewable energies and waste heat. In a further step, efficiency measures can be implemented on the generation side and the share of renewable and waste heat can be introduced and increased gradually. This must go hand-in-hand with predictions of future heat demand as well as with efficiency measures on the end use of heat [6].

Small modular district heating/cooling (DHC) grids have several benefits. They contribute to increase the local economy due to local value chains of local biomass supply. Local employment is enhanced as well as security of supply. The comfort for the connected household is higher as only the heat exchanger is needed in the basement of the buildings and no fuel purchase has to be organized. Small modular district heating/cooling grids can be fed by different heat sources, including from solar collectors, biomass systems, heat pumps and from surplus heat sources (e.g. heat that is not yet used from industrial processes or biogas plants). If the planning process is done in a sustainable way, small modular district heating/cooling grids have the advantage, that at the beginning only part of the system can be realized, and additional heat sources and consumers can be added later. This modularity requires well planning and appropriate dimensioning of the equipment (e.g. pipes). It reduces the initial demand for investment and can grow steadily, [7-9]. Therefore, it is important to support and promote renewable heating and cooling concepts, as shown in Figure 1, the core aim of the CoolHeating project.

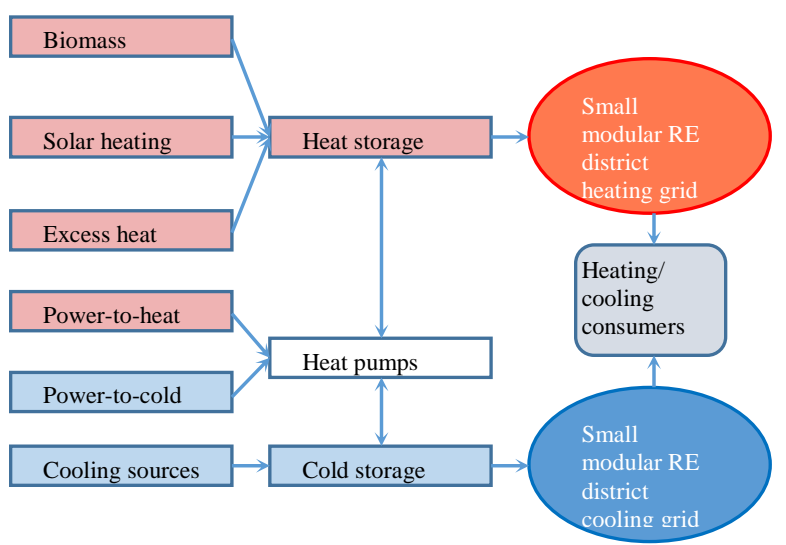

Fig 1 Small modular renewable heating/cooling concept

The objective of the CoolHeating project, funded by the EU's Horizon2020 program, is to support the implementation of small modular renewable heating and cooling grids for communities in South-Eastern Europe in Figure 2. This is achieved through knowledge transfer and mutual activities of partners in countries where renewable district heating and cooling examples exist (Austria, Denmark, Germany) and in countries which have less development in this sector (Croatia, Slovenia, Macedonia, Serbia, Bosnia and Herzegovina).

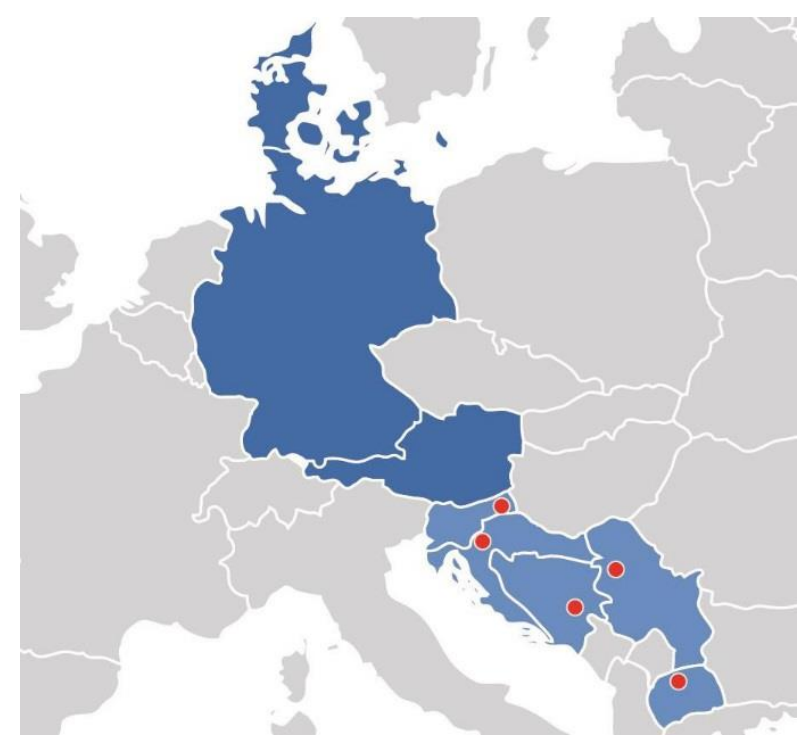

Fig 2 Target cities in South-Eastern Europe countries (light blue, red points)

Core activities, besides techno-economical assessments, included measures to stimulate the interest of communities and citizens to set-up renewable district heating systems. These lighthouse projects will have a long-term impact on the development of small modular renewable heating and cooling grids at the national levels in the target countries [10].

The CoolHeating project expects that the high interest of the participants will lead to joined forces on the local level to launch renewable district heating projects in the target communities of South-Eastern Europe - a region where generally good solar irradiation is available, one of which is the municipality of Visoko in Bosnia and Herzegovina.

\section{PROBLEM DESCRIPTION AND PROJECT AREA}

Bosnia and Herzegovina has high renewable energy sources (RES) potentials, especially in terms of biomass, sun and geothermal resources. The current use of biomass for individual heating is very low compared to the potentials. Most district heating systems are based on large scale fossil driven networks. The use of renewable sources and waste heat is non-existent. That is why transition to modern district heating and cooling systems based on renewable energy sources is one of the national priorities for Bosnia and Herzegovina. A number of strategic documents in Bosnia and Herzegovina, at the level of entities, canton and local communities, have 
dealt with energy consumption evaluations in buildings at the level of final energy and energy generating products (electric, heat, natural gas, oil and oil derivatives, coal and biomass) as well as possibilities for its reduction.

The selected target community in Bosnia is the municipality of Visoko. It is characterized by a population of 41,352 in 12,953 households. Part of the town is covered by a gas distribution system. However, due to relatively high price of natural gas, many consumers convert to other individual solutions for heating, such as wood, coal or electricity. Heating in Visoko municipality currently poses a problem for citizens and the local government in terms of excessive pollution. Air quality especially badly suffers during the heating season due to heavy use of coal for heating. Existing heating systems are mainly individual and currently dominated by coal as the cheapest energy source on the market. Therefore, municipality of Visoko is strongly interested to develop district heating system and find more sustainable solution for heating.

In this work, an analysis was performed for implementation of small modular district heating system in Visoko, covering several public buildings and few neighborhoods in north-western part of town. The area to be considered by the DH concept are shown in figure 3 .

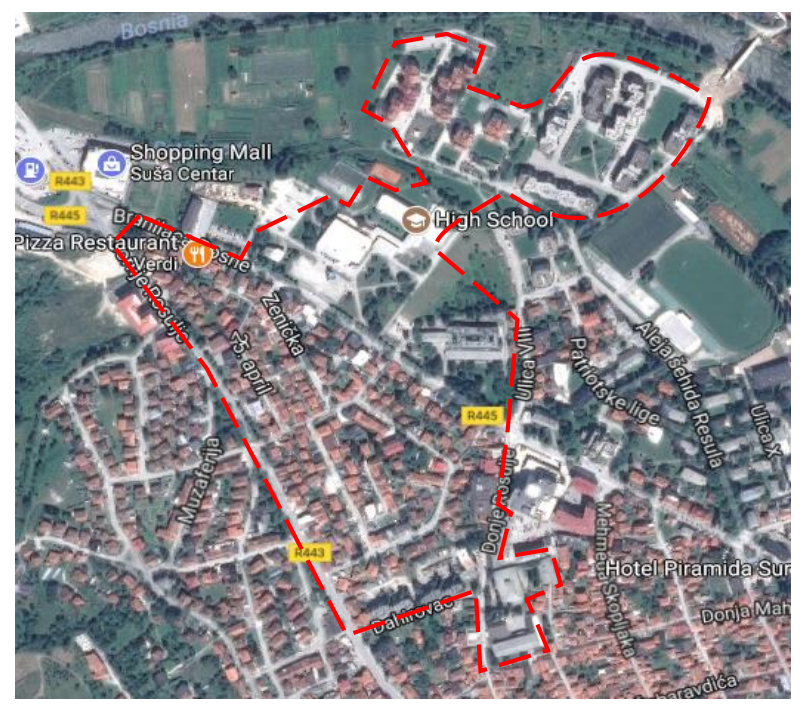

Fig 3 Micro-geographic location of the project

Evaluation was performed based on reliable data on energy consumption in buildings obtained by energy audits, statistical data, energy balance and energy development plans. Therefore, a top-down approach has been used. The results are summarized in Table 1 .

It is important to enhance the lack of applied energy efficiency measures on considered buildings. Residential and non-residential buildings have extremely large glazed areas with high heat transfer coefficients, walls with no insulation and large amounts of damage, oversized and unbalanced heating/cooling systems without regulation, etc. All this leads to high heat losses during heating season or gains during summertime.

Table 1 Heat demand of the project area

\begin{tabular}{|l|r|r|r|}
\hline Name or type of building & $\begin{array}{l}\text { Cond. } \\
\text { area } \\
{\left[\mathrm{m}^{2}\right]}\end{array}$ & $\begin{array}{l}\text { Specific } \\
\text { heat } \\
{\left[\mathrm{kWh} / \mathrm{m}^{2}\right]}\end{array}$ & $\begin{array}{l}\text { Heat } \\
\text { demand } \\
{[\mathrm{kWh}]}\end{array}$ \\
\hline Secondary school & 5.047 & 242 & 1.222 .163 \\
\hline Sports center & 3.350 & 347 & 1.162 .738 \\
\hline Collective housing Luke 1 & 12.510 & 180 & 2.251 .800 \\
\hline $\begin{array}{l}\text { Collective housing } \\
\text { Dahirovac }\end{array}$ & 12.000 & 180 & 2.160 .000 \\
\hline $\begin{array}{l}\text { Primary and Music } \\
\text { school }\end{array}$ & 3.027 & 180 & 544.860 \\
\hline Crèche & 1.065 & 180 & 191.700 \\
\hline $\begin{array}{l}\text { Individual housing } \\
\text { Hadžijina voda }\end{array}$ & 37.585 & 220 & 8.268 .700 \\
\hline Medical center & 4.895 & 180 & 682.654 \\
\hline Social work center & 390 & 200 & 78.000 \\
\hline Collective housing Luke 2 & 12.000 & 200 & 2.400 .000 \\
\hline
\end{tabular}

The project considers the design of a technical solution to ensure production of approximately $20 \mathrm{GWh}$ of heat per year to avoid emissions of 5,500 tons of $\mathrm{CO}_{2}$. The region considered in this paper contain a total conditioned area of around $92,000 \mathrm{~m}^{2}$ and very high heat consumption of around $210 \mathrm{kWh} / \mathrm{m}^{2}$. Different renewable energy sources were analyzed, as well as their combination, leading to an optimal and a very promising energy supply strategy due to its contribution to security of supply, financial stability, local economic development, local employment, etc.

Considering the technologies separately, it's important to note the following:

- location of Visoko in the river valley means large number of foggy days in winter time,

- no groundwater sites in the project area (based on previous researches conducted),

- no possibility of using industrial waste heat,

- insufficient quantities of usable waste available for biogas production,

- seasonal pit thermal energy storage preferred due to its lowest investment price compared to other storage technologies,

- use of photovoltaic panels installed on available roofs of public buildings attractive option for electricity generation to power other production units of the system,

- gas network existing in the project area.

No other requirements and obligations were included in the planning process, such as minimal efficiency, 
minimal grid density, emission limits etc., as there is lack of relevant legislation treating this topic.

\section{MODELLING AND OPTIMIZATION}

The DH system is planned to be constituted of a number of distribution networks interconnected by a transmission grid. Heat is to be produced at a variety of different production units comprising of heat pumps, biomass boilers and solar collectors. Peak load boilers using natural gas are integrated in the system in order to make the overall project financially feasible. These would start automatically if the heating output of the renewable energy sources DHC system is insufficient to cover demand. The choice of production technology is selected based on the geographic location of the site, available space for the production unit installation, availability and fuel prices.

Solar heating requires no fuel and can also store energy and release it during winter when there is less solar heat available. Thereby, heat storage is considered as a central part of the system. The power-to-heat conversion through heat pumps was found to furthermore help to balance the grid. Proximity of relatively large river passing through the town makes utilization of water to air heat pumps possible solution. Since the share of fluctuating renewable electricity production constantly increases, another way of producing heat is by utilizing renewable electricity generated by $\mathrm{PV}$ panels on location to power the heat pumps. These systems, with further help from heat storage, can also help balancing the grid. Scheme of production units in such modular DH system are shown in Figure 4.

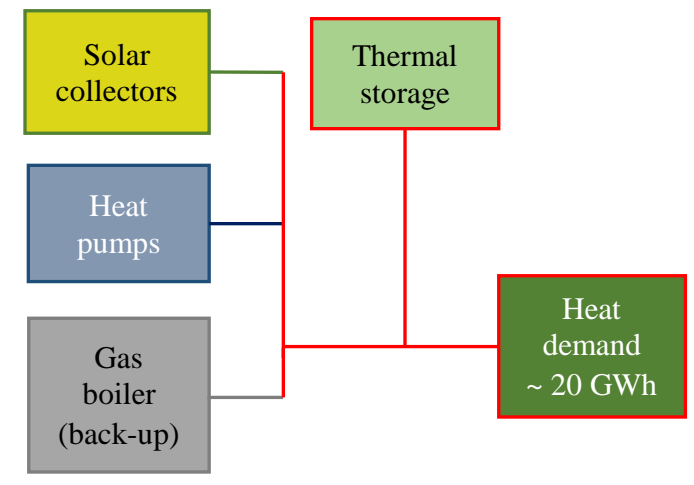

Fig 4 Scheme of production units in Visoko modular DH system

Forecast of the demand and determination of the capacities of the production units, as well as optimization of the operating mode itself, was performed by the specialized software EnergyPro, as shown in Figure 5. It is a modelling software used primarily in relation to district heating projects. It is used to carry out an integrated detailed technical and financial analysis of both existing and new energy projects. The software was used to plan the optimal production for the energy plant for a whole year. The period for the optimization was calculated per hour throughout the year with a detailed production plan. Inputs for the optimization are typically parameters such as content of stored energy at the beginning of the optimization period, expected energy demands within the period as well as all operating expenses. Calculations and optimization of the capacities (type and installed power in MW) and production (heat generation in $\mathrm{MWh}$ ) are based on inputs for all units, climate conditions, connection rate for private and collective housing facilities, prices of all energy sources, energy efficiency performance of the facilities, temperature level of DHS, heat losses assumption in the grid, operating time and so on. The software can optimize operation every hour based on operating costs such as maintenance costs, fuel and electricity prices, taxes, subsidies, etc. Therefore, it is the cheapest solution chosen that supplies the heat at any instant of time. When the operating costs are calculated for a scenario, investments and capital costs may be calculated so that the economically optimal solution may be determined. DH grid commencement and optimization, including consumer connections, is anticipated in the total length of $5,500 \mathrm{~m}$. It is however outside the scope of the current paper.

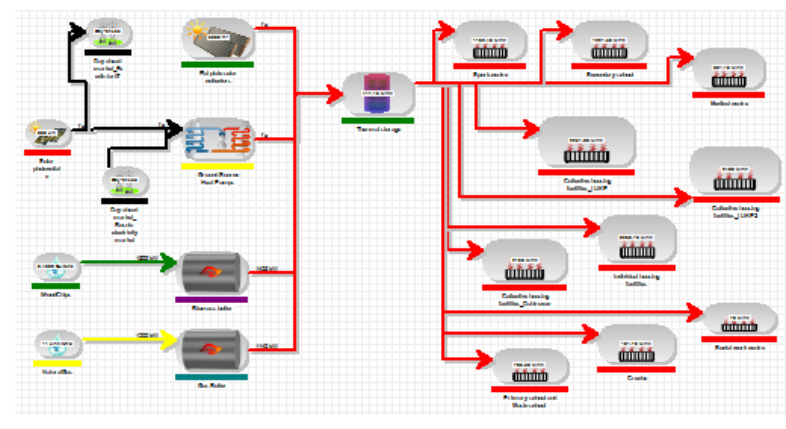

Fig 5 Scheme of heat production units and consumers calculated in EnergyPRO

\section{ANALYSIS OF LOADING AND STRUCTURE OPTIMIZATION OF COLLECTOR CARRIERS}

One of the essential parts of the solar system is a support structure. There are various designs of these structures depending on the location and the way of assembly. The angle of installation of the collector, which is one of the most important factors for the efficient operation of the system, depends on the support structure. The structure properties and design of a solar collector 
have an important influence on investment parameters of a solar thermal energy generation system. Due to stochastic and unpredictable external influences, the construction is exposed to variable loads. Variable loads cause fatigue and after a certain time the material becomes brittle and fracture can occur. Also, due to the strong wind that occurs below the collector, separation of the links with the base may occur.

This section examined the influence of external loads (wind, snow and external temperature) on solar collector carriers at their location. Construction design was performed based on knowledge of external influences and the numerical determination of the distribution of internal forces and moments - stress distribution within the structure. The designs were modeled in the CATIA software package and a load analysis was performed based on the finite element method in ANSYS software. As a result of the analysis, the distribution of the tension in the carrier has been determined. Determination of the ability of the structure to transfer the given influence is based on the material strength. The aim is to make the construction as realistic as possible, so that the results of global analysis truly simulate the real behavior of the construction under every possible influence, in order to obtain the most rational solution.

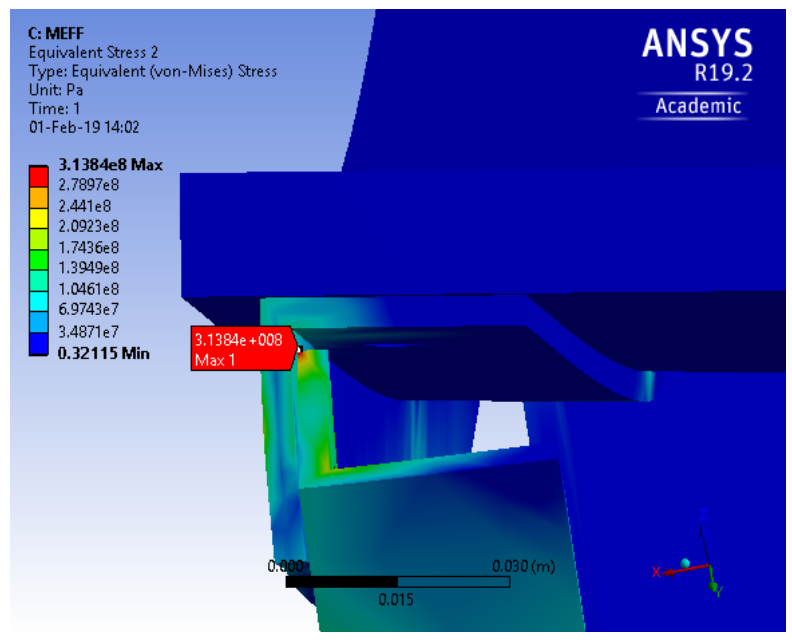

Fig 6 Stress occurring in solar collector carrier structure under external influences

Optimization of the structure was performed as regard the external load, taking into account local influencing parameters such as optimal tilt of panel, snow load, wind load considering direction and velocity, as well as external temperature. FEM analysis of the holder structure was used to optimize its structural lightweighting design and achieve savings in the structure material. The wind load characteristic was taken into account and its computational formula provided the magnitude of wind load $[11,12]$. Extreme temperatures and snow heights on the location during the period of last 100 years were taken in the analysis $[12,13]$. Then, the static performance of the solar collector was analyzed by using ANSYS Workbench and the worst working condition of each static characteristic was confirmed to service for the later structural optimization $[14,15]$.

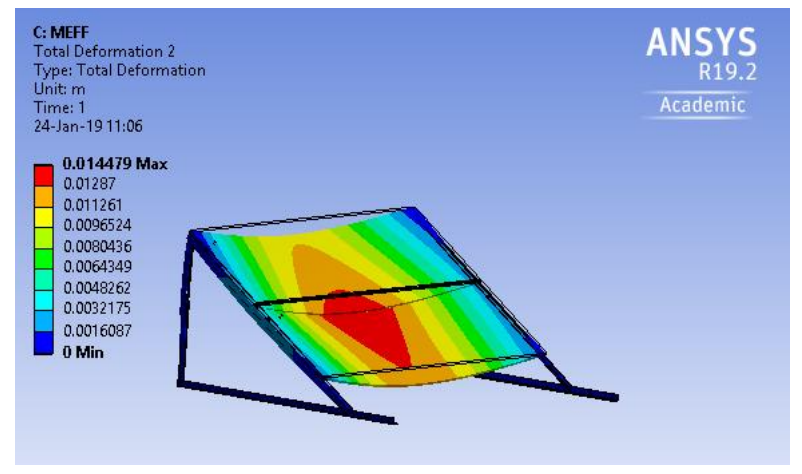

Fig 7 Deformation occurring in solar collector carrier structure under external influences

\section{RESULTS AND DISCUSSION}

Within this chapter, main characteristics of the conceptualized DH system considered through the CoolHeating project in the target municipality are presented. Then, results of calculation of selected sustainability indicators are presented and discussed, as well as integrated into a sustainability assessment.

Results of system optimization in terms of production units' capacities is the concept that plans a new DH grid using a 6.3 MW heat pump (from the river) as well as $5,000 \mathrm{~m}^{2}$ solar thermal collectors in combination with a $13,500 \mathrm{~m}^{3}$ seasonal storage, plus a natural gas peak load boiler. Overview of the calculated technical concept, optimized by EnergyPro tool is given in Table 2 .

Table 2 Technical data of the optimized DH concept

\begin{tabular}{|l|c|}
\hline DH grid length incl. consumer connections [m] & 5,500 \\
\hline Grid density [kWh/m/a] & 3,482 \\
\hline Annual heat losses of the DH grid [\%] & 6 \\
\hline Annual heat losses of the DH grid [MWh/a] & 1,129 \\
\hline Consumer needs heat [GWh/a] & 17 \\
\hline Total heat for DH grid incl. losses [GWh/a] & 18.13 \\
\hline Temperature level for DH grid, flow/return [ $\left.{ }^{\circ} \mathrm{C}\right]$ & $80 / 60$ \\
\hline DH grid operation in summertime & no \\
\hline Share of total heat for DH from solar thermal [\%] & 16 \\
\hline Share of total heat for DH from heat pump [\%] & 79 \\
\hline Share of total heat for DH from fossil peak boiler [\%] & 5 \\
\hline Thermal storage $\left[\mathrm{m}^{3}\right.$ ] & 13,500 \\
\hline
\end{tabular}

Economic and environmental indicators calculated are given in Table 3 and Table 4, respectively. As it can be seen from Table 3, CAPEX are higher for CoolHeating option then for reference case pertaining to current state of using fossil fuels and excessively polluting the environment. From the other side, total fuel costs in life time are by far higher in the option of the reference case, giving a ground for preference of CoolHeating option. 
Petrovic / Journal of Engineering and Science Research, 4(1) 2020, Pages:28-34

Table 3 Economic indicators, heat demand of $20 \mathrm{GWh} / \mathrm{a}$

\begin{tabular}{|l|r|r|l|}
\hline & $\begin{array}{l}\text { Reference } \\
\text { situation } \\
\text { Business as } \\
\text { usual) }\end{array}$ & $\begin{array}{l}\text { loolHeating } \\
\text { project }\end{array}$ & $\begin{array}{l}\text { Savings in } \\
\text { Life time of } \\
20 \text { years }\end{array}$ \\
\hline Investment $(€)$ & $1,033,830.00$ & $5,000,000.00$ & $-3,966,170.00$ \\
\hline Fuel cost $(€)$ & $16,390,843.60$ & $6,443,544.70$ & $9,947,298.90$ \\
\hline CAPEX $(€ / M W h)$ & 51.70 & 250.00 & \\
\hline OPEX $(€ / M W h)$ & 40.98 & 16.11 & \\
\hline
\end{tabular}

Thus, if CoolHeating projects are implemented, total savings in fuel costs in life time of 20 years would be 9,947,298.90 EUR, which is 2.51 times greater than total investment in CoolHeating project.

Table 4 summarizes environmental indicators. Considerable savings in emissions, namely $\mathrm{CO}_{2}, \mathrm{SO}_{2}$, $\mathrm{NO}_{\mathrm{x}}$ and PM10 and PM2.5 are achieved in CoolHeating option. Therefore, from the environmental aspect, the CoolHeating concept indisputably prevail over the option of reference case.

Table 4 Environmental indicators, heat demand of $20 \mathrm{GWh} / \mathrm{a}$

\begin{tabular}{|l|r|r|r|}
\hline & $\begin{array}{l}\text { Reference } \\
\text { situation } \\
\text { (Business } \\
\text { as usual) }\end{array}$ & $\begin{array}{l}\text { CoolHeating } \\
\text { project }\end{array}$ & $\begin{array}{l}\text { Savings in } \\
\text { Life time of } \\
\text { 20 years }\end{array}$ \\
\hline Emission $\mathrm{CO}_{2}(\mathrm{t})$ & $131,871.00$ & $67,406.44$ & $64,464.60$ \\
\hline Emission $\mathrm{SO}_{2}(\mathrm{t})$ & 238.27 & 120.12 & 118.10 \\
\hline Emission $\mathrm{NO}_{\mathrm{x}}(\mathrm{t})$ & $1,728.21$ & $1,166.58$ & 561.60 \\
\hline Emission $\mathrm{PM} 10(\mathrm{t})$ & 635.48 & 9.15 & 626.30 \\
\hline Emission $\mathrm{PM} 2.5(\mathrm{t})$ & 632.87 & 9.15 & 623.70 \\
\hline EnCO2 $(\mathrm{t} / \mathrm{MWh})$ & 0.330 & 0.169 & 0.161 \\
\hline
\end{tabular}

Moreover, advantages of this renewable energy project implementation go much more beyond the economic and environmental benefits. Numerous positive effects are realized, such as rational waste management, retention of existing jobs and creating new jobs, increasing the competitiveness of domestic industry. The project has a positive socio-economic impact, increasing the circulation of money within the local community and within the country, also attracting new investments.

Due to mentioned lack of applied energy efficiency measures on buildings in the project area, another option to consider is the energy efficiency measures implementation. However, it is impossible to have an effect on building owners to perform any measures at this stage. Later actual consumption charge will urge them to analyze cost-effectiveness and perform energy efficiency measures accordingly. This would give a rise to extension of the system to other parts of town using existing capacities.

Moreover, mechanical structure optimization based on FEM analysis revealed possible savings in the material of up to $7.8 \%$ compared to conventional solutions.

\section{CONCLUSION}

Heating in Visoko municipality currently poses a problem for citizens and the local government in terms of excessive pollution from individual boilers fired by solid fuels. It is critical to find an alternative for such situation, supporting and promoting renewable heating concepts. Key challenge concerning district heating and cooling sector nowadays is the integration of renewables and to show under which circumstances such systems are feasible and sustainable solutions. This is the core aim of the CoolHeating project, getting implemented in Visoko, which is trying to find optimal solution for small modular renewable heating system.

Different renewable energy sources analyzed lead to the optimal and very promising energy supply strategy due to its contribution to security of supply, financial stability, local economic development, local employment, etc. Set of economic and environmental indicators defined fully support sustainability analysis. Forecast of the demand and determination of the capacities of the heat production units, as well as optimization of the operating mode itself, was performed by the specialized software EnergyPro used for developing conceptual design of CoolHeating project in the target municipality.

The mechanical structure optimization of solar collector holders, taking into account external influence, revealed additional savings possibilities in the structure material compared to the most often used conventional solutions.

Results show CAPEX being higher for CoolHeating option then for the reference case. From the other side, total fuel costs in life time are by far higher in the option of the reference case (business as usual - doing nothing), giving a ground for preference to an option of CoolHeating renewable concept. Thus, if CoolHeating project is implemented, total savings in fuel costs in lifetime of 20 years would be 9,947,298.9 EUR, which is 2.51 times greater than total investment in CoolHeating project. Furthermore, considerable savings in emissions, namely $\mathrm{CO}_{2}, \mathrm{SO}_{2}, \mathrm{NO}_{\mathrm{x}}$ and PM10 and PM2.5 are achieved in CoolHeating scenario. Total savings in $\mathrm{CO}_{2}$ emissions in lifetime are nearly 55,000 tones. So, from the environmental aspect, the CoolHeating concept indisputably prevail over the option of reference case.

Comprising environmental, economic and social aspect, CoolHeating contributes to the overall sustainability in the field. At the end, all mentioned benefits will help the national government in fulfilling requirements of increasing renewable energy sources in final consumption and improving energy efficiency. 


\section{ACKNOWLEDMENTS}

The authors would like to thank the colleagues of WIP Renewable Energies, Güssing Energy Technologies $\mathrm{GmbH}$ and PlanEnergi, as well as the CoolHeating partners for their contributions in the project. The authors would like to thank the European Commission and the Innovation and Networks Executive Agency (INEA) for the support of the CoolHeating project. CoolHeating has received funding from the European Union's Horizon 2020 research and innovation program under grant agreement No 691679. The project duration is January 2016 to December 2018.

Disclaimer: The sole responsibility for the content of this paper lies with the authors. It does not necessarily reflect the opinion of the European Union. Neither the INEA nor the European Commission are responsible for any use that may be made of the information contained therein.

\section{REFERENCES}

[1] School of Business, Engineering and Science, Halmstad University Sweden. 2017. International review of district heating and cooling. Energy 137, 617-631.

[2] European Commission. 2016. An EU strategy on heating and cooling. Communication COM 2016, 51.

[3] Werner, S. 2017. International review of district heating and cooling. Energy 137, 617-631.

[4] Sayegh, M.A., Danielewicz, J., Nannou, T., Miniewicz, M., Jadwiszczak, P., Piekarska, K., Jouhara, H. 2017. Trends of European research and development in district heating technologies. Renewable and Sustainable Energy Reviews 68, 1183-1192.

[5] Connolly, D., Lund, H., Mathiesen, B.V., Werner, S., Möller, B., Persson, U., Boermans, T., Trier, D., Østergaard, P.A., Nielsen, S. 2014. Heat Roadmap Europe: Combining district heating with heat savings to decarbonise the EU energy system. Energy Policy 65, 475-489.

[6] Lund, H., Duic, N., Østergaard, P.A., Mathiesen, B.V. 2016. Smart energy systems and 4th generation district heating. Energy 110, 1-4.

[7] Rutz, D. et al. 2018. The role of biomass for small district heating grids for South-Eastern Europe - The CoolHeating project. Proceedings of the 26th European Biomass Conference and Exhibition, Copenhagen, Denmark.

[8] Rutz, D. et al. 2018. Small heating grids for communities in Balkan countries: The CoolHeating Project. Proceedings of the 5th International Solar District Heating Conference, Graz, Austria.
[9] Rutz, D. et al. 2017. The Combination of Biomass with Solar Thermal Energy and other Renewables for Small Heating Grids: The CoolHeating Project. Proceedings of the 25th European Biomass Conference and Exhibition, Stockholm, Sweden.

[10] Jensen, L.L. et al. 2016. Best Practice Examples of Renewable District Heating and Cooling, Report of the CoolHeating project.

[11] Shademan, M., Hangan, H. 2010. Wind loading on solar panels at different azimuthal and inclination angles. The Fifth International Symposium on Computational Wind Engineering (CWE2010), North Carolina, USA.

[12] Shademan, M., Barron, R.M., Balachandar, R., Hangan, H. 2014. Numerical simulation of wind loading on ground-mounted solar panels at different flow configurations, Canadian Journal of Civil Engineering 41(8), 728-738.

[13] Bohren, A., Brunner, A., Abegg, P. 2016. Simulation of Very High Snow Loads on Solar Thermal Collectors. Energy Procedia 91, 325-329.

[14] Liu, J.P., Ye, B.Y., Xun, G., Shi, Y.P. 2013. Mechanical Analysis and Structural Optimisation of the Parabolic Trough Solar Collector. Key Engineering Materials 579-580, 916-923.

[15] Mihailidis, A., Panagiotidis, K., Agouridas, K. 2009. Analysis of solar panel support structures. 3rd ANSA \& Meta International Conference, Halkidiki, Greece. 